\title{
Biological active compounds and antioxidant activity of plants from the collection of Central Siberian Botanical Garden. II. Lamiaceae
}

\author{
Evgeniya A. Karpova ${ }^{1 *}$, Tatyana A. Kukushkina ${ }^{1}$, Tatyana M. Shaldaeva ${ }^{1}$, and Yuliya A. \\ Pshenichkina ${ }^{1}$ \\ ${ }^{1}$ Central Siberian Botanical Garden, Siberian branch of Russian Academy of Sciences, \\ Zolotodolinskaya Str., Novosibirsk, 630090, Russia
}

\begin{abstract}
The contents of the major groups of biologically active compounds (catechins, flavonoids, tannins, saponins, pectin, and carotenoids) and total antioxidants (TA) in the leaves and the flowers of Agastahe rugosa_(Fisch. \& C.A. Mey.) Kuntze, Betonica officinalis L., Dracocephalum nutans L., Mentha caucasica Gand., Nepeta grandiflora M. Bieb., Origanum vulgare L., Scutellaria baicalensis Georgi (Lamiaceae), collected during the flowering period of 2019 in "Collections of living plants indoors and outdoors" USU 440534 of Central Siberian Botanical Garden SB RAS, Novosibirsk, were studied. The concentrations of constituent majority were higher in leaves compared to flowers. In the leaves, maximums of catechins $\left(15.60 \mathrm{mg} \cdot \mathrm{g}^{-1}\right.$, B. officinalis), flavonoids $\left(61.5 \mathrm{mg} \cdot \mathrm{g}^{-1}, \mathrm{~S}\right.$. baicalensis $)$, saponins $(178.5$ $\mathrm{mg} \cdot \mathrm{g}^{-1}, D$. nutans $)$, and protopectin $\left(106.0 \mathrm{mg} \cdot \mathrm{g}^{-1}, B\right.$. officinalis $)$ were revealed. In the flowers, maximums of tannins $\left(247.4 \mathrm{mg} \cdot \mathrm{g}^{-1}, O\right.$. vulgare $)$ and pectin $\left(16.31 \mathrm{mg} \cdot \mathrm{g}^{-1}, S\right.$. baicalensis) were found. Maximum of total antioxidant contents (TAC) $\left(6.21 \mathrm{mg} \cdot \mathrm{g}^{-1}\right)$ was detected in the leaves of $O$. vulgare. Positive correlations between TAC and the content of tannins and flavonoids were revealed. The results confirm health benefits of the studied species and contribute to the knowledge of the distribution of saponins and pectins in the Lamiaceae.
\end{abstract}

\section{Introduction}

Lamiaceae Lindl. is a large plant family of mostly shrubs and herbs, which are popular due to various biological effects on human health, including antioxidant and antimicrobial properties closely associated with a variety of secondary metabolites [1]. Numerous members of the Lamiaceae family have been used in folk medicine for many years. Currently, antitussive, diuretic, anti-asthmatic, antiseptic, antispasmodic, and febrifuge activities of the herbs were revealed [2]. Some species displayed antiviral properties [3]. Chemical composition of Lamiaceae members combines a variety of terpenoids with iridoid glycosides, flavonoids and other phenolic compounds [4]. Carotenoids and flavonoids were reported to be crucial determinants of antioxidant properties of plants [5]. Lamiaceae species were also examined for pectic substances [6]. Pectin was proved to have diverse biological activities including lipid and cholesterol level lowering effects, serum glucose

\footnotetext{
*Corresponding author: karpova@.csbg.nsc.ru
} 
content lowering effects, and anti-cancer activities [7]. In addition, polysaccharides of pectin possess antioxidant activity and may provide auxiliary functions for other active antioxidant components [8]. Meanwhile, variation of health promoting compounds through locations and plant body parts are in focus of current investigations with particular emphasis on the constituents with high antioxidant activity [9].

The collection of Central Siberian Botanical Garden of Siberian Branch of Russian Academy of Sciences (CSBG SB RAS) USU 440534 in Novosibirsk contains the members of several Lamiaceae genera known for their positive health effects. Most of them belong to the Nepetoideae Burnett subfamily. It is the most numerous in the Lamiaceae family and it is considered a source of antioxidants [1]. Betonica officinalis L. (Lamioideae Harley) and Scutellaria baicalensis (Scutellarioideae Prantl) were documented to have medical properties [2].

The aim of this study was to determine the profiles of biological active compounds (in terms of quantities of selected major groups of compounds in the leaves and flowers) of 7 Lamiaceae species and to compare their antioxidant properties.

\section{Material and methods}

The leaves and flowers of Agastahe rugosa_(Fisch. \& C.A. Mey.) Kuntze, Betonica officinalis L., Dracocephalum nutans L., Mentha caucasica (Gand.) Briq., Nepeta grandiflora M. Bieb., Origanum vulgare L., Scutellaria baicalensis Georgi were collected during the flowering period of 2019 from "Collections of living plants indoors and outdoors" USU 440534 of CSBG SB RAS in the garden plot located in a forest-steppe region with gray forest soil and the mean yearly temperature/precipitation of $1.8^{\circ} \mathrm{C} / 448$ $\mathrm{mm}$. Air-dried plant material were ground up using a household mill. Weighted samples were extracted according to the proper methods. Dry matter concentrations in the samples were calculated by the gravimetric method. Total catechin contents $(\mathrm{C})$ were determined in the ethanol extracts by the vanillin- $\mathrm{HCl}$ method [10]. Total flavonoid contents (F) determination was performed by spectrophotometry at $415 \mathrm{~nm}$ after a reaction of complexation of flavone and flavonols with aluminium chloride in the aqueous ethanol extract. The flavonoid concentrations were calculated as rutin equivalents [11]. For hydrolysable tannin (T) estimation, spectrophotometric measurement of intensity of reaction of aqueous extract of the leaves and flowers with a $2 \%$ aqueous solution of ammonium molibdate at $420 \mathrm{~nm}$ was carried out. The state standard of tannin was used as outside standard [12]. Total saponins contents as crude saponin (S) were determined by the gravimetric method. Powdered sample was extracted with chloroform using Soxhlet extractor to remove lipids and resins. Then, the residue was extracted by $50,60,96 \%$ ethanol sequentially (twice each concentration for $30 \mathrm{~min}$ ) at $\mathrm{T}=70{ }^{\circ} \mathrm{C}$. The combined extract was evaporated to $5 \mathrm{ml}$, and a 7-fold volume of acetone was added. After 18 hours, the resulting precipitate was filtered out, dried at $70^{\circ} \mathrm{C}$, weighed, and the content of crude saponin was calculated [13]. The contents of pectins (P) and protopectins (PP) (after hydrolysis) were determined by spectrophotometric method $(480 \mathrm{~nm})$ based on obtaining a specific yellow-orange staining of uronic acids with thymol in a sulfuric acid medium after removal sugars from the samples. The percentage of pectic substances was calculated using a calibration curve for galacturonic acid from Sigma (St. Louis, MO, USA) [14]. The total carotenoids (Car) was determined spectrophotometrically after extraction by acetone and ethanol consecutively. The absorption of the solution was measured at wavelengths corresponding to absorption maxima of chlorophyll a $\left(\mathrm{C}_{\mathrm{a}}\right)(662 \mathrm{~nm})$, chlorophyll $\mathrm{b}\left(\mathrm{C}_{\mathrm{b}}\right)$ $(644 \mathrm{~nm})$, and carotenoids $(440.5 \mathrm{~nm})$ [15]. All above tests were performed in triplicate, and the biochemical parameters were calculated in $\mathrm{mg}$ per $\mathrm{g}$ of absolutely dry weight $\left(\mathrm{mg} \cdot \mathrm{g}^{-1} \mathrm{DW}\right)$. 
Total antioxidant contents (TAC) was determined in aqueous ethanol extracts $(70 \%$ $\mathrm{v} / \mathrm{v})$ by amperometric method using flow injection system with amperometric detection "Tsvet Yauza-01-AA" and calculated as gallic acid (GA) equivalents [16]. These tests were performed in five replication. All the data were processed in the Statistica 10.0 software (Statsoft Inc., Tulsa, OK, USA), were reported as mean \pm standard error of three (or five) replicates, and were compared by Duncan's multiple range test. Differences between the means were considered statistically significant at the $5 \%$ level $(p<0.05)$. Linear regression was calculated by means of Multiple Regression analysis. Reliability of the influence of the factors ('species' and 'plant organ') was evaluated by two-way ANOVA.

\section{Results}

The results of the tests showed a significant variation in all parameters by the species (Table). The table shows the parameters of the species that are most rich in biological active compounds.

Table. Concentrations of biological active compounds $\left(\mathrm{mg}^{\mathrm{g}} \mathrm{g}^{-1} \mathrm{DW}\right)$ and antioxidant activities ( $\mathrm{mg}$ gallic acid $\left.\cdot \mathrm{g}^{-1} \mathrm{DW}\right)$ of the Lamiaceae species

\begin{tabular}{|c|c|c|c|c|c|}
\hline & $\begin{array}{l}\text { Betonica } \\
\text { officinalis }\end{array}$ & $\begin{array}{l}\text { Dracocephalum } \\
\text { nutans }\end{array}$ & $\begin{array}{l}\text { Nepeta } \\
\text { grandiflora }\end{array}$ & $\begin{array}{l}\text { Origanum } \\
\text { vulgare }\end{array}$ & $\begin{array}{l}\text { Scutellaria } \\
\text { baicalensis }\end{array}$ \\
\hline $\mathrm{C}$ & $\frac{15.60 \pm 0.02^{\mathrm{a}}}{3.07 \pm 0.01^{\mathrm{b}}}$ & $\frac{1.04 \pm 0.01^{\mathrm{g}}}{0.94 \pm 0.00^{\mathrm{i}}}$ & $\frac{0.97 \pm 0.01^{\mathrm{h}}}{0.66 \pm 0.01^{\mathrm{j}}}$ & $\frac{2.09 \pm 0.01^{\mathrm{c}}}{1.45 \pm 0.00^{\mathrm{d}}}$ & $\frac{1.39 \pm 0.01^{\mathrm{e}}}{1.11 \pm 0.01^{\mathrm{f}}}$ \\
\hline $\mathrm{T}$ & $\frac{125.3 \pm 1.8^{\mathrm{d}}}{89.0 \pm 1.3^{\mathrm{e}}}$ & $\frac{202.8 \pm 1.8^{\mathrm{b}}}{205.9 \pm 1.8^{\mathrm{b}}}$ & $\frac{149.8 \pm 1.3^{\mathrm{c}}}{79.5 \pm 1.5^{\mathrm{f}}}$ & $\frac{242.4 \pm 4.7^{\mathrm{a}}}{247.4 \pm 2.1^{\mathrm{a}}}$ & $\frac{205.2 \pm 3.7^{b}}{90.8 \pm 1.5^{c}}$ \\
\hline$F$ & $\frac{21.9 \pm 0.6^{\mathrm{e}}}{9.2 \pm 0.2^{\mathrm{g}}}$ & $\frac{60.2 \pm 0.8^{\mathrm{a}}}{47.0 \pm 0.6^{\mathrm{b}}}$ & $\frac{19.8 \pm 0.4^{\mathrm{f}}}{7.6 \pm 0.1^{\mathrm{g}}}$ & $\frac{48.4 \pm 0.9^{\mathrm{b}}}{43.0 \pm 0.4^{\mathrm{c}}}$ & $\frac{61.5 \pm 1.1^{\mathrm{a}}}{39.7 \pm 0.5^{\mathrm{d}}}$ \\
\hline$P$ & $\frac{4.96 \pm 0.07^{\mathrm{g}}}{7.27 \pm 0.16^{\mathrm{e}}}$ & $\frac{5.28 \pm 0.05^{\mathrm{g}}}{6.15 \pm 0.10^{\mathrm{f}}}$ & $\frac{8.99 \pm 0.00^{\mathrm{c}}}{7.94 \pm 0.08^{\mathrm{d}}}$ & $\frac{5.21 \pm 0.10^{\mathrm{g}}}{4.06 \pm 0.03^{\mathrm{h}}}$ & $\frac{14.62 \pm 0.18^{b}}{16.31 \pm 0.43^{a}}$ \\
\hline PP & $\frac{106.0 \pm 0.8^{\mathrm{a}}}{59.2 \pm 0.5^{\mathrm{h}}}$ & $\frac{68.2 \pm 0.2^{\mathrm{g}}}{78.3 \pm 0.1^{\mathrm{f}}}$ & $\frac{103.6 \pm 1.9^{\mathrm{b}}}{67.5 \pm 1.00^{\mathrm{g}}}$ & $\frac{81.7 \pm 0.8^{\mathrm{e}}}{86.2 \pm 0.5^{\mathrm{d}}}$ & $\frac{97.7 \pm 0.5^{\mathrm{c}}}{59.5 \pm 0.8^{\mathrm{h}}}$ \\
\hline Car & $\frac{0.80 \pm 0.01^{b}}{0.13 \pm 0.00^{h}}$ & $\frac{0.39 \pm 0.01^{\mathrm{e}}}{0.19 \pm 0.00^{\mathrm{g}}}$ & $\frac{0.64 \pm 0.01^{\mathrm{d}}}{0.12 \pm 0.00^{\mathrm{h}}}$ & $\frac{0.72 \pm 0.01^{\mathrm{c}}}{0.33 \pm 0.00^{\mathrm{f}}}$ & $\frac{0.91 \pm 0.01^{\mathrm{a}}}{0.06 \pm 0.00^{\mathrm{i}}}$ \\
\hline $\mathrm{S}$ & $\frac{70,6 \pm 3,0^{\mathrm{e}}}{57,2 \pm 3,7^{\mathrm{f}}}$ & $\frac{178,5 \pm 4,8^{\mathrm{a}}}{94,5 \pm 6,7^{\mathrm{d}}}$ & $\frac{115,2 \pm 5,8^{\mathrm{c}}}{147,9 \pm 7,2^{\mathrm{b}}}$ & $\frac{177,3 \pm 5,5^{\mathrm{a}}}{126,7 \pm 5,2^{\mathrm{c}}}$ & $\frac{115,2 \pm 5,6^{c}}{149,5 \pm 5,8^{b}}$ \\
\hline TAC & $\frac{0.30 \pm 0.02^{\mathrm{i}}}{0.43 \pm 0.01^{\mathrm{h}}}$ & $\frac{2.04 \pm 0.03^{\mathrm{c}}}{1.54 \pm 0.00^{\mathrm{e}}}$ & $\frac{0.66 \pm 0.02^{\mathrm{g}}}{0.46 \pm 0.01^{\mathrm{h}}}$ & $\frac{6.21 \pm 0.01^{\mathrm{b}}}{7.32 \pm 0.03^{\mathrm{a}}}$ & $\frac{1.75 \pm 0.01^{\mathrm{d}}}{1.30 \pm 0.00^{\mathrm{f}}}$ \\
\hline
\end{tabular}

Parameters of the leaves are in numerator, and parameters of the flowers are in denominator; means followed by the same letter are not significantly different according to Duncan's test $(p<0.05)$

Total catechin content and TAC varied most significantly. Meanwhile, ranges of variability of these parameters in the leaves were more widely compared to these in the flowers. Protopectin and tannin were the least variable. Ranges of variability of protopectin in the leaves and in the flowers were identical (1.5 times), and tannins in the flowers varied greater (3.1 times) than in the leaves (1.6 times). The rest of the studied parameters varied 3-6 times, and ranges of their variability in the flowers were the same or wider compared to the leaves.

The concentrations of majority of constituents in the leaves were higher compared to the flowers. In the leaves, a high contents of catechins $\left(15.60 \mathrm{mg} \cdot \mathrm{g}^{-1}\right.$ in B. officinalis), flavonoids (61.5 and $60,2 \mathrm{mg} \cdot \mathrm{g}^{-1}$ in $S$. baicalensis and $D$. nutans, respectively), tannins (242.4, 205.2, and $202.8 \mathrm{mg} \cdot \mathrm{g}^{-1}$ in $O$. vulgare, S. baicalensis, and D. nutans), saponins (178.5 and $177.3 \mathrm{mg} \cdot \mathrm{g}^{-1}$ in $D$. nutans and $O$. vulgare), pectin (14.62 $\mathrm{mg} \cdot \mathrm{g}^{-1}$ in $S$. baicalensis), and protopectin (106.0 and $103.6 \mathrm{mg} \cdot \mathrm{g}^{-1}$ in B. officinalis and $N$. grandiflora) were noted. In the flowers, a high contents of tannins $\left(247.4\right.$ and $205.9 \mathrm{mg} \cdot \mathrm{g}^{-1}$ in $O$. vulgare 
and D. nutans) and maximal content of pectin $\left(16.31 \mathrm{mg} \cdot \mathrm{g}^{-1}\right.$ in $S$. baicalensis $)$ were determined.

Maximum of TAC $\left(6.21 \mathrm{mg} \cdot \mathrm{g}^{-1} \mathrm{GA}\right)$ was found in the leaves of $O$. vulgare. $S$. baicalensis thus had the largest number of high (tannins) and maximal (flavonoids, pectin, carotenoids) biochemical parameters, but its TAC was low (1.75 $\left.\mathrm{mg} \cdot \mathrm{g}^{-1} \mathrm{GA}\right)$. Meanwhile, $O$. vulgare with maximal TAC possessed highest tannin content. The correlation between TAC and total tannin content of the samples was revealed (Fig. 1), as well as between TAC and total flavonoid content.
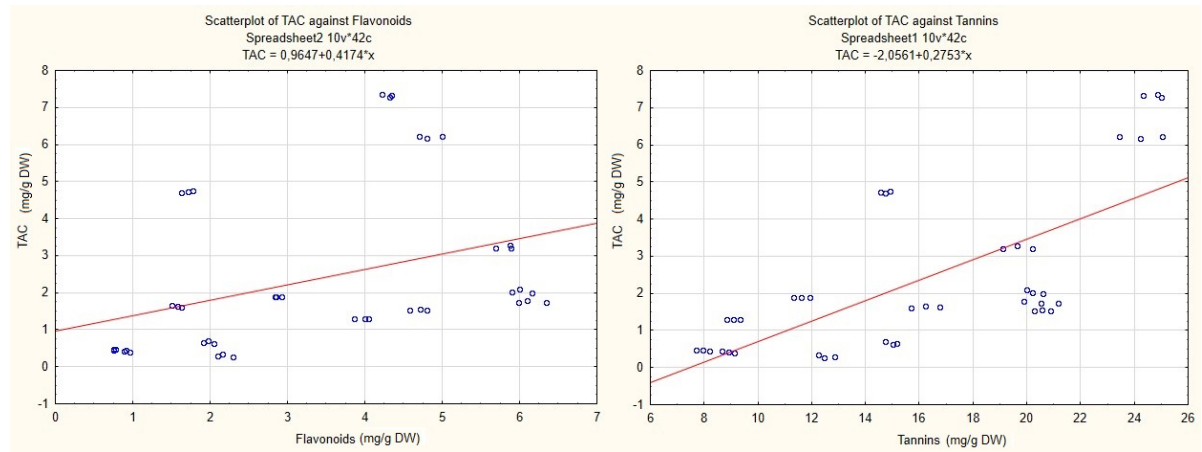

Fig. 1. Relationship among total antioxidant content and contents of flavonoids and tannins in the leaves and flowers of the Lamiaceae species $(n=42)$. The correlation coefficients are 0.37 and 0.71 , respectively

The results of the two-way ANOVA revealed reliable effects of species, plant organ (leaf or flower) and combination of these factors on the biochemical parameters. Antioxidant activity of the samples was mainly determined by species and combination of the factors, and it did not depend on plant organ.

Thus, when cultivated in Western Siberia, each studied species had a special profile of bioactive compounds in the leaves and in the flowers. S. baicalensis and O. vulgare possessed elevated values of the majority of biochemical parameters. The results are consistent with previous data on high antioxidant activity of members of the Nepetoideae [1]. The obtained data confirmed the results of a previous study on the prospects of the Lamiaceae species as a source of flavonoids, tannins and carotenoids with high antioxidant activity. The levels of the parameters were the same or higher compared to these reported in previous investigations [17]. Saponins and pectins of this family have been poorly studied. The obtained results contribute to knowledge of distribution of these multifunctional compounds in representatives of Lamiaceae. Pectin content in the studied samples varied significantly, and maximal levels of pectin in the leaves and flowers of $S$. baicalensis correspond with high levels of pectin in some species of this family [18]. The found correlation between total flavonoid contents and total tannin contents, and TAC corresponds with similar correlations revealed previously [19-21].

\section{Conclusions}

The results adds an information to the data on the patterns of biological active compounds of the species Agastahe rugosa, Betonica officinalis, Dracocephalum nutans, Mentha caucasica, Nepeta grandiflora, Origanum vulgare, and Scutellaria baicalensis. High levels of flavonoids (including catechins), tannins and pectins coupled with carotenoids and saponins provide antioxidant properties and point to a good therapeutic potential of these species. 
The work was financially supported by the draft State assignments of the Central Siberian Botanical Garden of the Siberian Branch of the Russian Academy of Sciences No. AAAA-A17-1170126100515 and No. AAAA-A17-117012610053-9 within the framework of a government contract and with material of CSBG representing USFs (Unique Scientific Facilities) "Collections of living plants indoors and outdoors" USU 440534.

\section{References}

1. K. Carović-Stanko, M. Petek, M. Grdiša, J. Pintar, D. Bedeković, M. Herak Ćustić, Z. Šatović, Czech J. Food Sci. 34, 377 (2016)

2. M. Uritu, C.T. Mihai, G. Stanciu, G. Dodi, T. Alexa-Stratulat, A. Luca, M. LeonConstantin, R. Stefanescu, V. Bild, S. Melnic, B.I. Tamba, Pain Res. Manag. 2018, 7801543 (2018)

3. I.E. Lobanova, E.I. Filippova, G.I. Vysochina, N.A. Mazurkova, Plant Life of Asian Russia 2, 64 (2016)

4. F. Naghibi, M. Mosaddegh, S. Mohammadi, A. Ghorbani, Iran J. Pharm. Res. 2, 63 (2005)

5. D.P. Xu, Y. Li, X. Meng, T. Zhou, Y. Zhou, J. Zheng, J.J. Zhang, H.B. Li, Int. J. Mol. Sci. 18, 96 (2017)

6. E.P. Kukhta, V.Y. Chirva, M.R. Borovskii, M.A. Tolmacheva, I.V. Eroshenko, Chem. Nat. Compd. 18, 251 (1982)

7. A. Wikiera, M. Irla, M. Mika, Postepy Hig. Med. Dosw. 68, 590 (2014)

8. S.T. Minzanova, V.F. Mironov, D.M. Arkhipova, A.V. Khabibullina, L.G. Mironova, Y.M. Zakirova, V.A. Milyukov, Polymers (Basel) 10, 1407 (2018)

9. I.B.H. Yahia, R. Jaouadi, R. Trimech, M. Boussaid, Y. Zaouali, Biochem. Syst. Ecol. 84, 8 (2019)

10. T.A. Kukushkina, A.A. Zykov, L.A. Obukhova Common cuff (Alchemilla vulgaris L.) as a source of medicines, in Proceedings of the VII International Congress on Actual Problems of Creating New Drugs of Natural Origin, 3-5 July 2003, St. Petersburg, Russia (2003)

11. V.V. Belikov, M.S. Shreiber, Farmatsiya 1, 66 (1970)

12. L.M. Fedoseeva, Chemistry of Plant Row Material, 3, 45 (2005)

13. A.V. Kiseleva, T.A. Volkhonskaya, V.E. Kiselev, Biologically Active Substances of Medicinal Plants of Southern Siberia (Nauka, Novosibirsk, 1991)

14. V.I. Kriventsov, Proceedings of State Nikitsky Botanical Gardenю,109, 128 (1989)

15. Methods of biochemical research of plants, ed. by A.I. Yermakov (Leningrad, 1987)

16. P.A. Fedina, A.Ya., N.I. Yashin, Chemistry of Plant Row Material, 2, 91 (2010)

17. M. Shanaida, O. Golembiovska, N. Hudz, P. Wieczorek, Curr. Issues Pharm. Med. Sci. 31, 194 (2018)

18. J. Lu, J. Li, R. Jin, S. Li, J. Yi, J. Huang, Int. J. Biol. Macromol. 131, 323 (2019)

19. R. Amarowicz, A. Troszyńska, N. Baryłko-Pikielna, J. Food Lipids 11, 278 (2004)

20. V. Katalinic, M. Milos, T. Kulisic, M. Jukic, Food Chem. 94, 550 (2006)

21. R. Farhoudi, Free Radical Bio. Med. 108, 24 (2017) 